\title{
FAKTOR-FAKTOR YANG MEMPENGARUHI PRESENTASI BOKONG PADA IBU HAMIL DI RUMAH SAKIT UMUM KOTA PADANGSIDIMPUAN TAHUN 2013
}

\author{
Setiawaty Suluhbara \\ Prodi Kebidanan Padangsidimpuan Poltekkes Kemenkes Medan
}

\begin{abstract}
Abstra k
Pengawasan Antenatal Care penting bagi wanita hamil mulai dari trimester I sampai trimester III agar komplikasi dalam kehamilan seperti Presentasi Bokong dapat dikenali secara dini, dalam 11\% kematian perinatal disebabkan oleh Presentasi Bokong. Diketahuinya faktor-faktor presentasi bokong pada ibu hamil di rumah sakit umum daerah kota padangsidimpuan. Metode Penelitian Kuantitatif dengan menggunakan data sekunder dari Medical Record di RSUD Kota Padangsidimpuan dengan sampel total 43 ibu hamil. Jumlah Presentasi Bokong 43 dari 1081 ibu hamil pada tahun 2013,berdasarkan paritas mayoritas pada multipara sebanyak 24 ibu hamil (55,81\%).Berdasarkan Faktor Ibu Presentasi Bokong mayoritas dengan keadaan panggul sempit sebanyak 30 ibu hamil (69,77\%),berdasarkan Faktor Janin Presentasi Bokong mayoritas pada keadaan Hidramnion atau Oligohidramnion sebanyak 18 ibu hamil (41,86\%),berdasarkan lilitan tali pusat sebanyak 23 ibu hamil (53,49\%),berdasarkan kelainan uterus sebanyak 9 ibu hamil $(20,93 \%)$ dan berdasarkan Kunjungan ANC mayoritas pada kunjungan 2 kali sebanyak 13 ibu hamil (30,23\%). Terdapat kesenjangan karakteristik variabel paritas, ibu hamil dengan Multipara lebih besar kemungkinan terjadinya Presentasi Bokong.
\end{abstract}

Kata kunci : Presentasi bokong, Ibu hamil

\section{PENDAHULUAN}

Menurut World Health Organization (WHO) mencatat pada tahun 2007 angka kematian ibu lebih dari 300 hingga 400/100.000 kelahiran hidup dengan penyebab kematian adalah perdarahan $28 \%$,eklamsi $24 \%$,infeksi $11 \%$,abortus $5 \%$,partus lama/macet $5 \%$,emboli obstetri $3 \%$,komplikasi puerperium 8\%,lain-lain 16\%.Sedangkan Angka Kematian Bayi (AKB) Tahun 2009 cenderung meningkat dari tahun 2008 yaitu 17,5 per 1000 kelahiran hidup menjadi 20,1 per 1000 kelahiran hidup. Kematian bayi tersebut disebabkan oleh 28,9\% karena IUFD (Intra Uteri Fetal Death),asfiksia 12,2\%, BBLR (Berat Badan Lahir Rendah) 20,4\%,Malpresentasi $11 \%$ cacat bawaan $4,8 \%$, sepsis $8,9 \%$ dan lain-lain $13,8 \%$.

Angka kematian ibu (AKI) yang merupakan salah satu indikator terhadap kesehatan sebuah negara saat ini masih sangat tinggi di Indonesia.Menurut hasil Survei Demografi Kesehatan Indonesia (SDKI) Tahun 2012 AKI per 100.000 kelahiran hidup adalah adalah Brunai Darussalam 13,Singapura 14,Malaysia 62, Thailand 110,Vietnam 150,Philipina 230 dan Indonesia 359.Dari data tersebut ternyata AKI Indonesia tertinggi dari ketujuh Negara tersebut yaitu 359 per 100.000 kelahiran hidup,sementara AKI yang terendah adalah Brunai Darussalam.Berdasarkan survei demografi kesehatan indonesia (SDKI),AKI per 100.000 kelahiran hidup menurun secara bertahap.Dari 390 per 100.0000 kelahiran hidup (Tahun 1991) menjadi 334 (Tahun 1997),307
(Tahun 2003) dan 228 (Tahun 2007), Tahun 2012 meningkat menjadi 359 (INFID,2012).

Adapun penyebab kematian bayi salah satunya adalah Malpresentasi yaitu Presentasi Dahi,Presentasi Muka ,Presentasi Majemuk,dan Presentasi Bokong.Namun demikian dikarenakan Jenis Malpresentasi yang sangat beragam,Peneliti memfokuskan pada Presentasi Bokong.Presentasi Bokong terjadi disebabkan oleh Paritas,Faktor Ibu,Faktor Janin,Lilitan Tali Pusat,Kelainan Uterus,Kunjungan ANC yang kurang.Faktor Ibu meliputi Plasenta Previa dan panggul sempit sedangkan Faktor Janin meliputi Hidrosefalus atau anensefalus,Gemelli,Hidramnion atau Oligohidramnion dan Prematuritas.Oleh karena itu Presentasi Bokong memerlukan intervensi dan tindakan yang tepat untuk meminimalkan terjadinya kematian bayi yaitu dengan cara melaksanakan kunjungan ANC pada masa kehamilan.

Berdasarkan hasil dari study pendahuluan yang dilakukan di RSUD Kota Padangsidimpuan, diperoleh data Ibu Hamil Januari 2013 - Desember 2013, Jumlah semua Ibu Hamil sebanyak 1081 Orang. Sedangkan Ibu Hamil yang mengalami Presentasi Bokong sebanyak 43 orang.

\section{TUJUAN PENELITIAN}

Untuk mengetahui Faktor-faktor yang mempengaruhi Presentasi Bokong Pada Ibu Hamil di Rumah Sakit Umum Daerah Kota Padangsidimpuan Tahun 2013. 


\section{MANFAAT PENELITIAN}

1. Secara Teoritis

Meningkatkan pengetahuan dalam upaya pemeliharaan, peningkatan dan pemanfaatan fasilitas kesehatan yang tersedia.

2. Secara Praktik

Data atau informasi hasil penelitian ini dapat menjadi dimanfaatkan Petugas Rumah Sakit Kota Padangsidimpuan terutama petugas dibagian bersalin dalam mengantisipasi terjadinya resiko dalam menangani masalah Presentasi Bokong.

\section{METODE PENELITIAN}

Jenis penelitian yang dilakukan adalah penelitian deskriptif, dengan untuk melihat kejadian presentasi bokong pada ibu hamil dengan variabl paritas, faktor ibu, faktor janin, lilitan tali pusat, kelainan uterus dan kunjungan ANC yang kurang.

\section{Lokasi dan Waktu Penelitian}

Penelitian ini dilakukan di Rumah Sakit Umum Kota Padangsidimpuan berdasarkan asumsi penulis bahwa

Rumah sakit tersebut juga merupakan Rumah Sakit Rujukan sehingga data tentang ibu Bersalin Partus Lama yang disebabkan Presentasi Bokong cukup lengkap untuk mewakili seluruh penderita lainnya.

\section{Populasi dan Sampel}

Populasi : semua ibu Hamil yang diagnosanya adalah terjadinya Presentasi Bokong pada Ibu Hamil di Rumah Sakit Umum Kota Padangsidimpuan Tahun 2013 dengan jumlah 43 orang.

Sampel: semua populasi dijadikan sampel

\section{Metode Pengumpulan Data}

Pengumpulan data dilaksanakan dengan menggunakan metode dokumentasi yang diperoleh dari Medical Record RSUD Kota Padangsidimpuan Tahun 2013.

\section{Analisa Data}

Analisa data dilakukan secara deskriptif dengan melihat presentase data yang telah dikumpul dan disajikan dalam tabel distribusi frekuensi.

\section{HASIL PENELITIAN}

\section{Hasil}

Distribusi Proporsi Ibu Hamil dengan Presentasi Bokong Terhadap jumlah pasien di RSUD Kota Padangsidimpuan Tahun 2013

\begin{tabular}{cccc}
\hline Tahun & $\begin{array}{c}\text { Jumlah Ibu } \\
\text { Hamil }\end{array}$ & $\begin{array}{c}\text { Jumlah Ibu Hamil } \\
\text { dengan Presentasi } \\
\text { Bokong }\end{array}$ & $\%$ \\
\hline 2013 & 1081 & 43 & 3,98 \\
\hline
\end{tabular}

Distribusi Proporsi Ibu Hamil dengan Presentasi Bokong Berdasarkan Paritas di RSUD Kota Padangsidimpuan Tahun 2013

\begin{tabular}{clcc}
\hline No & Paritas & Jumlah & $\%$ \\
\hline 1 & Primipara & 11 & 25,59 \\
2 & Sekundipara & 8 & 18,60 \\
3 & Multipara & 24 & 55,81 \\
\hline & Total & 43 & 100 \\
\hline
\end{tabular}

Dari hasil penelitian menunjukkan bahwa angka kejadian tertinggi ditemukan pada paritas Multipara sebanyak 24 orang $(55,81 \%)$. Hal ini sesuai dengan teori Winkjosastro (2007) bahwa hampir semua ibu hamil dengan Multipara lebih besar kemungkinan terjadinya Malpresentasi khususnya Presentasi Bokong.Karena otototot dalam kehamilan umumnya mengalami peregangan dan kelonggaran karena adanya penyesuaian dengan perkembangan janin,diantaranya adalah otot abdomen, dasar pelvis, dan uterus, dimana ketiga otot tersebut saling mempengaruhi satu sama lain dan berperan dalam terjadinya presentasi bokong.Untuk mencegah terjadinya Malpresentasi pada Ibu Hamil dianjurkan untuk melaksanakan Program KB yaitu 2 anak lebih baik.

Distribusi Proporsi Ibu Hamil dengan Presentasi Bokong Berdasarkan Faktor Ibu di RSUD Kota Padangsidimpuan Tahun 2013

\begin{tabular}{ccc}
\hline No $\quad$ Faktor Ibu & Jumlah & $\%$ \\
\hline 1 Plasenta Previa & 13 & 30,23 \\
2 Panggul sempit & 30 & 69,77 \\
& & \\
\hline Total & 43 & 100 \\
\hline
\end{tabular}

Dari hasil penelitian di atas ditemukan angka kejadian pada perlekatan plasenta yaitu plasenta previa sebanyak 13 orang $(30,23 \%)$. Hal ini sesuai dengan teori Winkjosastro (2007) bahwa Plasenta previa sangat mempengaruhi terjadinya Malpresentasi.Hal tersebut dikarenakan letak plasenta yang rendah sehingga mengubah posisi janin menjadi posisi yang abnormal. Sedangkan kejadian panggul sempit ditemukan angka kejadian tertinggi pada ukuran panggul luar yaitu $<80 \mathrm{~cm}$ sebanyak 30 orang $(69,77 \%)$. Hal ini sesuai dengan teori Manuaba (2008) bahwa hampir semua Ibu Hamil dengan Panggul Sempit akan mengalami Malpresentasi.Panggul sempit dapat mengganggu fiksasi dari kepala janin.

Distribusi Proporsi Ibu Hamil dengan Presentasi Bokong Berdasarkan Faktor Janin di RSUD Kota Padangsidimpuan Tahun 2013

\begin{tabular}{llcc}
\hline No & \multicolumn{1}{c}{ Faktor Janin } & Jumlah & $\%$ \\
\hline 1 Hidrosefalus atau & 5 & 11,63 \\
2 anensefalus & 12 & 27,91 \\
3 Gemelli & 18 & 41,86 \\
4 Hidramnion atau & 8 & 18,60 \\
$\quad$ Oligohidramnion & & \\
$\quad$ Prematuritas & & \\
\hline \multicolumn{1}{c}{ Total } & 43 & 100 \\
\hline
\end{tabular}


Dari hasil penelitian tabel diatas ditemukan angka kejadian pada Bentuk Kepala Janin (Hidrosefalus/Anensefalus) sebanyak 5 orang (11,63\%). Hal ini sesuai dengan teori Winkjosastro (2007) bahwa ibu hamil dengan Hidrosefalus/Anensefalus sangat mempengaruhi terjadinya Malpresentasi dikarenakan Bentuk kepala Janin yang mengganggu fiksasi dari kepala janin. Sedangkan gemelli sebanyak 12 orang $(27,91 \%)$. Hal ini sesuai dengan teori Manuaba (2008) bahwa Ibu hamil dengan Gemelli sangat mempengaruhi Letak Janin. Umumnya pada kehamilan kembar, janin menyesuaikan dirinya dalam rahim. Angka kejadian Hidramnion dan ditemukan angka kejadian tertinggi pada Jumlah air Ketuban dengan > $2000 \mathrm{cc}$ (Hidramnion) dan < $500 \mathrm{cc}$ (Oligohidramnion) sebanyak 18 orang (41,86\%). Dikarenakan banyaknya air ketuban pada janin sehingga menyebabkan janin lebih leluasa melakukan pergerakan. Prematuritas juga mempengaruhi kejadian presentasi bokong dalam kehamilan, angka kejadiannya sebesar $(18,60 \%)$. Hal tersebut terjadi karenakan ukuran janin yang kecil menyebabkan janin leluasa melakukan pergerakan di dalam rahim dan pada bayi premature ukuran kepala masih kecil sehingga fiksasi kepala tidak sempurna. Oleh karena itu untuk mencegah hal tersebut terjadi perlu dilakukan kunjungan ANC yang sesuai standar untuk memantau keadaan atau kondisi janin didalam kandungan.

Distribusi Proporsi Ibu Hamil dengan Presentasi Bokong Berdasarkan Lilitan Tali Pusat di RSUD Kota Padangsidimpuan Tahun 2013

\begin{tabular}{lrcc}
\hline No & Tali Pusat & Jumlah & $\%$ \\
\hline 1 & Lilitan Tali Pusat & 23 & 53,49 \\
2 & Tali Pusat Normal & 20 & 46,51
\end{tabular}

Total $\quad 43 \quad 100$

Dari hasil penelitian tabel diatas ditemukan angka kejadian tertinggi pada Lilitan Tali Pusat sebanyak 23 orang $(53,49 \%)$. Hal ini sesuai dengan teori Winkjosastro (2007) bahwa hampir semua Ibu Hamil dengan lilitan tali pusat sangat mempengaruhi Letak janin.Hal tersebut dikarenakan tali pusat yang terlalu panjang sehingga memungkinkan janin terlilit tali pusat dan menyulitkan janin melakukan pergerakan.

Distribusi Proporsi Ibu Hamil dengan Presentasi Bokong

Berdasarkan Kelainan Uterus di RSUD Kota Padangsidimpuan Tahun 2013

\begin{tabular}{cccc}
\hline No & Uterus & Jumlah & $\%$ \\
\hline 1 & Kelainan Uterus & 9 & 20,93 \\
2 & Uterus Normal & 34 & 79,07 \\
& & \\
\hline & Total & 43 & 100 \\
\hline
\end{tabular}

Dari hasil penelitian tabel di atas ditemukan angka kejadian Kelainan Uterus sebanyak 9 orang $(20,93 \%)$. Hal ini sesuai dengan teori Sarwono (2005) bahwa Ibu hamil dengan kelainan uterus mempengaruhi tejadinya Malpresentasi pada janin.Tumor dari uterus yang mendesak uterus dan kelainan bawaan uterus, seperti uterus arkuatus yang dapat mengubah letak janin.

Distribusi Proporsi Ibu Hamil dengan Presentasi Bokong Terhadap Kunjungan ANC di RSUD Kota Padangsidimpuan Tahun 2013

\begin{tabular}{cccc}
\hline No & Kunjungan ANC (kali) & Jumlah & $\%$ \\
\hline 1 & 1 & 7 & 16,28 \\
2 & 2 & 13 & 30,23 \\
3 & 3 & 11 & 25,58 \\
4 & 4 & 12 & 27,91 \\
& & & \\
\hline
\end{tabular}

Dari hasil penelitian tabel di atas ditemukan angka kejadian tertinggi pada 2 kali kunjungan ANC selama Ibu hamil sebanyak 13 orang $(30,23 \%)$. Hal ini sesuai dengan teori Manuaba (2008) bahwa Ibu hamil dengan kunjungan ANC yang kurang sangat mempengaruhi terjadinya kelainan letak pada janin.Oleh karena itu untuk mencegah terjadinya Kelainan Letak pada janin dengan melaksanakan Kunjungan ANC sesuai standart yang berlaku.

\section{SIMPULAN DAN SARAN}

\section{Simpulan}

1. Presentasi Bokong memerlukan penanganan yang serius tepat dan cepat berdasarkan kebutuhan Ibu Hamil baik dengan melakukan Kunjungan ANC sesuai dengan standart yang berlaku untuk menghindari terjadinya persalinan dengan Presentasi Bokong serta kematian bagi Ibu dan Bayi.

2. Jumlah Ibu Hamil dengan Presentasi Bokong di RSUD Kota Padangsidimpuan termasuk rendah jika dibanding dengan insiden di beberapa Rumah Sakit di Indonesia juga menurut literatur

\section{Saran}

1. Disarankan kepada ibu agar melakukan pemeriksaan ANC (Ante Natal Care) secara teratur paling sedikit 4 kali yaitu 1 kali pada trimester I,1 kali pada trimester II dan 2 kali pada trimester III.

2. Disarankan kepada ibu agar mengatur jarak kehamilan dengan mengikuti program $\mathrm{KB}$,untuk kesehatan serta keselamatan ibu dan bayi.

3. Disarankan kepada petugas kesehatan untuk lebih mengenali masalah yang terjadi pada ibu hamil sehingga lebih mudah mendeteksi komplikasi kehamilan.

4. Dianjurkan kepada bidan yang bertugas di rumah sakit supaya mendapatkan kesempatan training dalam penanganan seluruh kasuskasus kebidanan agar terwujud bidan yang benar mampu dalam menangani kasus-kasus 
kebidanan khususnya kasus Presentasi Bokong.

\section{DAFTAR PUSTAKA}

Anonim. Presentasi Bokong. (Dikutip dari http://medlinux.blogspot.com/. Diakses Tanggal 28 November 2010. Pukul 13. 35 WIB)

Benson dan Pernoll. 2009. Buku Saku Obstetri dan Ginekologi. Jakarta: EGC.

Fachrudin, Amir. 2009. Presentasi Bokong. (di kutip dari http://i8.photobucket.com/albums/a46/ef med2001/emirbannerfix.gif. Diakses tanggal 20oktober 2010. Pukul 13.25)

Hidayat, A.A. 2007. Metodologi Penelitian Kebidanan Teknik Analisa Data. Jakarta: Salemba Medika.

Imade. 2008. Penanganan untuk Kehamilan dan persalinan letak sungsang. (Dikutip dari http://imadeharyoga.com/2008/10/penangananuntuk-kehamilan-dan-persalinan-letak-sungsang/. Diakses tanggal 19 November 2010. Pukul 14.00 WIB)

Liu, David. 2008. Manual Persalinan. Jakarta : EGC
Manuaba, Ida Bagus Gde. 2008. Gawat Darurat Obstetri dan Obstetri Ginekologi Sosial untuk Profesi Bidan. Jakarta: EGC

Rohani, Dkk. 2010. Asuhan Kebidanan pada Masa Persalinan. Jakarta: Salemba Medika.

Rukiyah dan yulianti. 2010. Asuhan Kebidanan IV (Patologi Kebidanan). Jakarta: Buku Kesehatan.

Sukarsa, Rizkar. 2007. Letak Sungsang. (Dikutip dari http://immahamtaro.wordpress.com/category. Diakses tanggal 29 November 2010. Pukul 19.35 WIB).

Sulistyawati, Ari. 2010. Asuhan Kebidanan pada Ibu Bersalin. Jakarta: Salemba Medika.

Varney. 2010. Buku Asuhan Kebidanan. Jakarta:EGC

Winkjosastro, Hanifa. 2007. Ilmu Kebidanan. Jakarta : Yayasan Bina Pustaka sarwono Prawirohardjo.

Yatinem. Asuhan Kebidanan pada Multigravida Letak Sungsang. (Dikutip dari http://yatinem.wordpress.com/2009/02/22/asuhan -kebidanan-dengan-multigravida-letak sungsang/. Diakses Tanggal 17 Oktober 2010. Pukul 11.25 WIB) 